\title{
Techno-Economic Assessment of Concentrating Solar Power and Wind Hybridization in Jordan
}

\author{
Osama Ayadi ${ }^{*}$, Ishraq A. Alsalhen ${ }^{1}$ \\ 1 Mechanical Engineering Department, The University of Jordan, Jordan \\ * Corresponding author's e-mail: o.ayadi@ju.edu.jo
}

\begin{abstract}
The variable renewable wind and solar resources have experienced a significant growth on its rate of deployment as a clean and competitive alternative for conventional power sources in Jordan. However, the variability of these sources have brought many technical challenges to grids. This paper presents a hybrid system that provides a firma capacity and improves dispatchability with an interesting financial perspective. This hybrid system includes a wind farm and a concentrated solar power plant with thermal energy storage. The performance analysis was conducted in terms of final yield and capacity factor, while the economic analysis investigated the levelized cost of electricity LCOE. The hybrid plant was simulated and optimized using TRNSYS 17 energy simulation software, minimizing the LCOE and considering a capacity factor higher than $65 \%$ as a constraint. Solar multiple and storage size were considered as decision variables. A strong complementarity between wind and direct normal solar radiation was observed in the selected location in Jordan, which emphasizes the attractiveness of the selected hybrid system. The optimal configuration of the CSP-wind hybrid system was obtained with a solar field of a 2.6 solar multiple and a 5 hours energy storage. The achieved capacity factor was $94 \%$, and the LCOE is lower than those resulted for standalone CSP plants.
\end{abstract}

Keywords: concentrated solar power, wind, thermal energy storage, hybridization

\section{INTRODUCTION}

Increased penetration of renewable energy occurs during the periods of high availability of solar sources. The generated energy may exceed the grid limits and a curtailment of these sources may be required. The economic limit on the penetration of such renewable sources occurs depending on the grid flexibility. The grid flexibility can be improved by introducing suitable energy storage systems. The concentrated solar power with thermal energy storage system is an important option for both the flexibility of the grid and the energy storage systems. It constitutes a relatively cheap energy storage system compared to other storage technologies. One of the main barriers to the commercial development of CSP technology is its high capital cost and therefore its high electricity production cost. On the other hand, wind as an energy source is considered as relatively low cost. However, its power output is variable due to the wind speed variations. Hybridization of CSP with wind technologies combines the low cost of electricity generation of wind and relatively cheap thermal energy storage option by CSP Plants.

Considering the weather conditions and market demand profile in Jordan, a scenario was modeled, simulated, and evaluated in terms of dispatchability and firmness. As such, despite the ability of CSP to supply electricity on demand through cost-effective thermal energy storage, lower cost wind electricity has achieved much larger market penetration. However; the increased grow of non-dispatchable renewable electricity in the grid has resulted in a greater focus on the controllable generation. The controllable generation can guarantee the security of supply and reduce the constraints on the transmission system. 


\section{RESEARCH OBJECTIVE}

In this context, the research assessed the Hybrid CSP technology as a solar energy configuration which meets predictability and dispatchability conditions; especially where the energy demand is high relative to the energy storage and primary resources.

The main objective of this study is to introduce a real CSP-Wind scenario for the current weather and market conditions in Jordan. The specific aims of this project are:

1) to evaluate the dispatchability and firmness for a selected hybrid CSP-Wind system plant,

2) to assess the advantages and technical constraints for applying such plants in Jordan,

$3)$ to evaluate the levelized cost of electricity (LCOE) for the plants in Jordan

\section{METHODOLOGY}

The research work is based on the simulation of the proposed hybrid system plant. The simulation of the plant requires data collection on the weather conditions and the technical parameters of the system in addition to the related published results of similar topics in the field. The following steps describe the methodology adopted for carrying out this study.

- Step (1): Literature review is carried out, including the overview of the related studies in the field.

- Step (2): Hybrid model consisting of CSPWind system plant to meet a base load demand was proposed.

- Step (3): The size of the grid connected Hybrid CSP-Wind system plant was selected as 50MWe. This scale was chosen to make use of the available technical parameters of similar CSP plant scale like Andasol 350 MW.

- Step (4): TRNSYS17 was used to simulate the grid connecting the system plant. Geographical location and metrological data of the selected location (Ma'an - AL-Shoubak) city was used. Technical input (CSP collectors) data were obtained from the design document related to a CSP plant which published data for a same size plant (Solar Millinium, 2015)

- Step (5): Hybrid model technical performance analysis was carried out. Efficiency and capacity factor of the hybrid system plant were calculated.
- Step (6): Different scenarios for the proposed CSP plant were assumed, 1) CSP without storage system, 2) CSP with storage system.

- Step (7): For each scenario, the capacity factor of the CSP plant was calculated

- Step (8): Based on the above, results were concluded.

\section{HYBRID CSP-WIND SYSTEM PLANT MODELING}

The system Plant designed consists of three blocks: solar field, storage system, and a power block which is shown in Figure 1.

The CSP power plant consists of three blocks: solar field, storage system, and power block. The solar field consists of the collector array which collects the incident solar rays and concentrates it on a focal line with heat transfer fluid (HTF). The HTF transfers the solar heat to the storage system and to the power block where the electricity is generated. The storage system consists of a heat exchanger to exchange the heat between the HTF and the storage medium. Additionally, there is a storage tank which consists of hot and cold tanks containing the molten salt. The power block consists of a heat exchanger, steam turbine, and a generator in order to convert the solar energy to electricity. The wind power plant consists of a number of wind turbines. The electricity generated by these turbines is directly injected to the grid.

The proposed system plant consists of these two plants as a hybrid configuration in order to benefit from both renewable energy sources. In the case of feasible wind speed, the produced wind energy will be injected directly in the grid, and if the electrical power produced from the wind turbine does not meet the demand, the remaining power will be injected from the solar thermal power plant, where a solar radiation and thermal energy conversion to the electrical energy is carried out through the steam turbine. In the case when both energy sources (solar and wind) meets the desired electrical power generation, and there is remaining thermal energy, it will be stored in the storage system, which will be used when there is lack of solar radiation and wind power generation.

Electrical demand is to be met by the wind turbines in first place. Then, if there is still a shortage of the injected power to the grid, the solar thermal plant will compensate it. Consequently, 


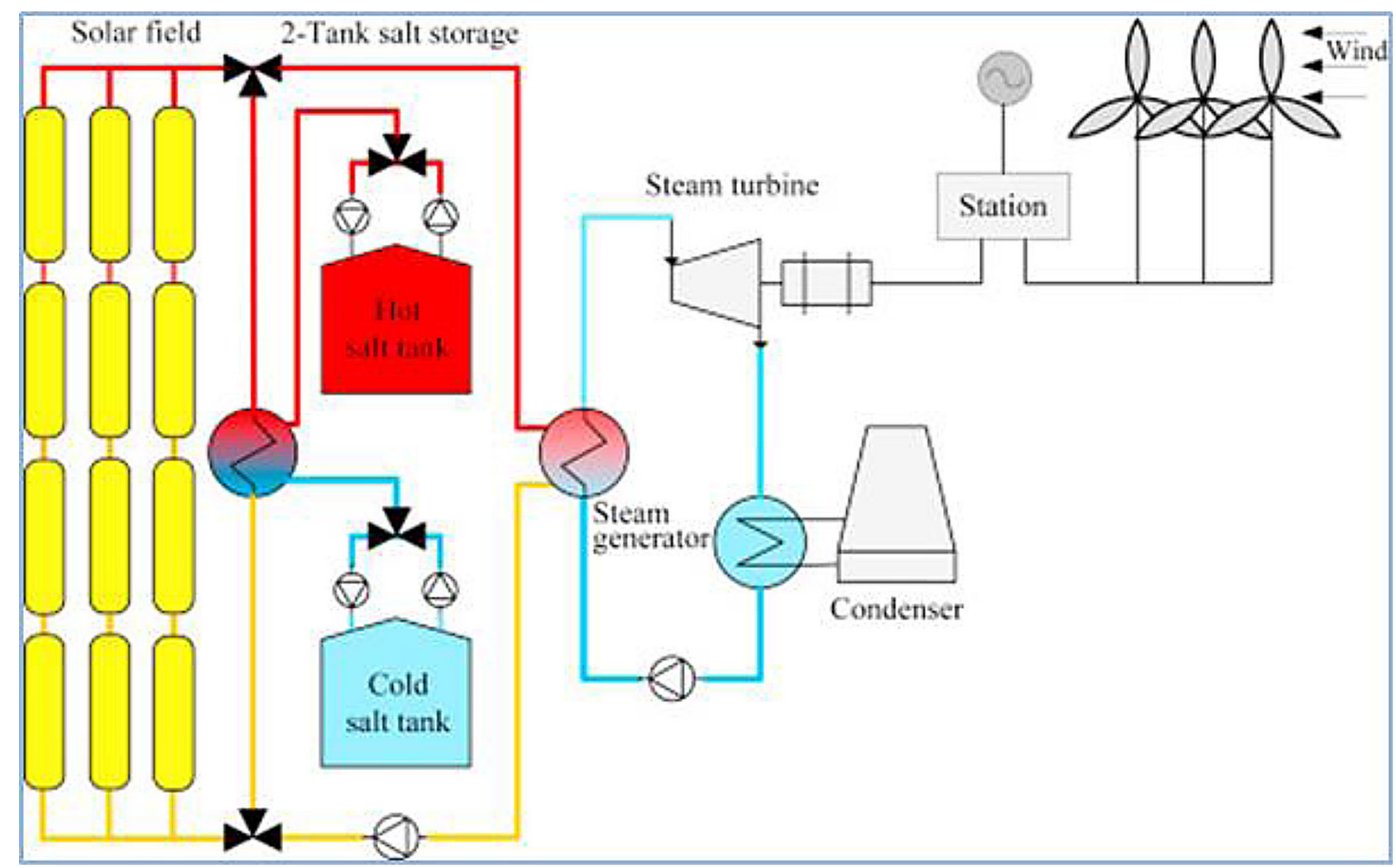

Figure 1. Hybrid CSP-Wind block diagram

in the case of abundant solar radiation and thermal energy production, a production of superfluous thermal energy will occur. This energy should be returned to the storage system tank; hence, an increased storage system size is needed. However, when the thermal and wind energy sources fit the demand for most of the day for the entire year, the hours of power generation shortage will decrease, so the needed storage capacity will decrease as well.

The hybrid CSP-Wind system was modeled and simulated; a detailed description of the model is found in the following sections. The model in the figure 1 was developed and simulated using TRNSYS software, as shown in Figure 2.

\section{SIMULATION RESULTS}

In order to conduct a performance analysis for the hybrid system plant under study, several parameters were calculated. The solar multiple is a way to express the solar field aperture area as a function of the power cycle capacity. A solar multiple of 1 is the aperture area required to deliver sufficient thermal energy to the power cycle to drive it at its nameplate capacity under the designed conditions. The desired usable thermal capacity of the storage system is the multiplication of the design point power cycle thermal load, and the required storage hours. The net capacity factor of the system plant is the unitless ratio of an actual electrical energy output over a given period of time to the maximum possible electrical energy output over the same amount of time. The maximum possible energy output of a given installation assumes its continuous operation at full nameplate capacity over the relevant period of time. The grid output is the total energy output of the CSP plant, and the energy output of the wind plant.

\section{REQUIRED SOLAR FIELD}

The simulation results of the parameters of the CSP power plant at solar multiple 1 with storage volume 20,000 $\mathrm{m}^{3}$ is shown in Figure 3. The maximum power production reached for this configuration was $49,116 \mathrm{~kW}$. The capacity factor of the CSP plant was 0.31 , while the overall capacity factor of the system plant was 0.58 . The power output of the grid is shown in Figure 4.

Figure 4 shows the shortage of the power generation where there was no feasible power generation from the solar thermal power plant, low solar radiation, and shortage of the storage capacity to compensate this drop in the power generation. Furthermore, there was no feasible wind generation at these times during the year.

In order to meet the minimum drops at the grid output, i.e. during the winter season and cloudy 


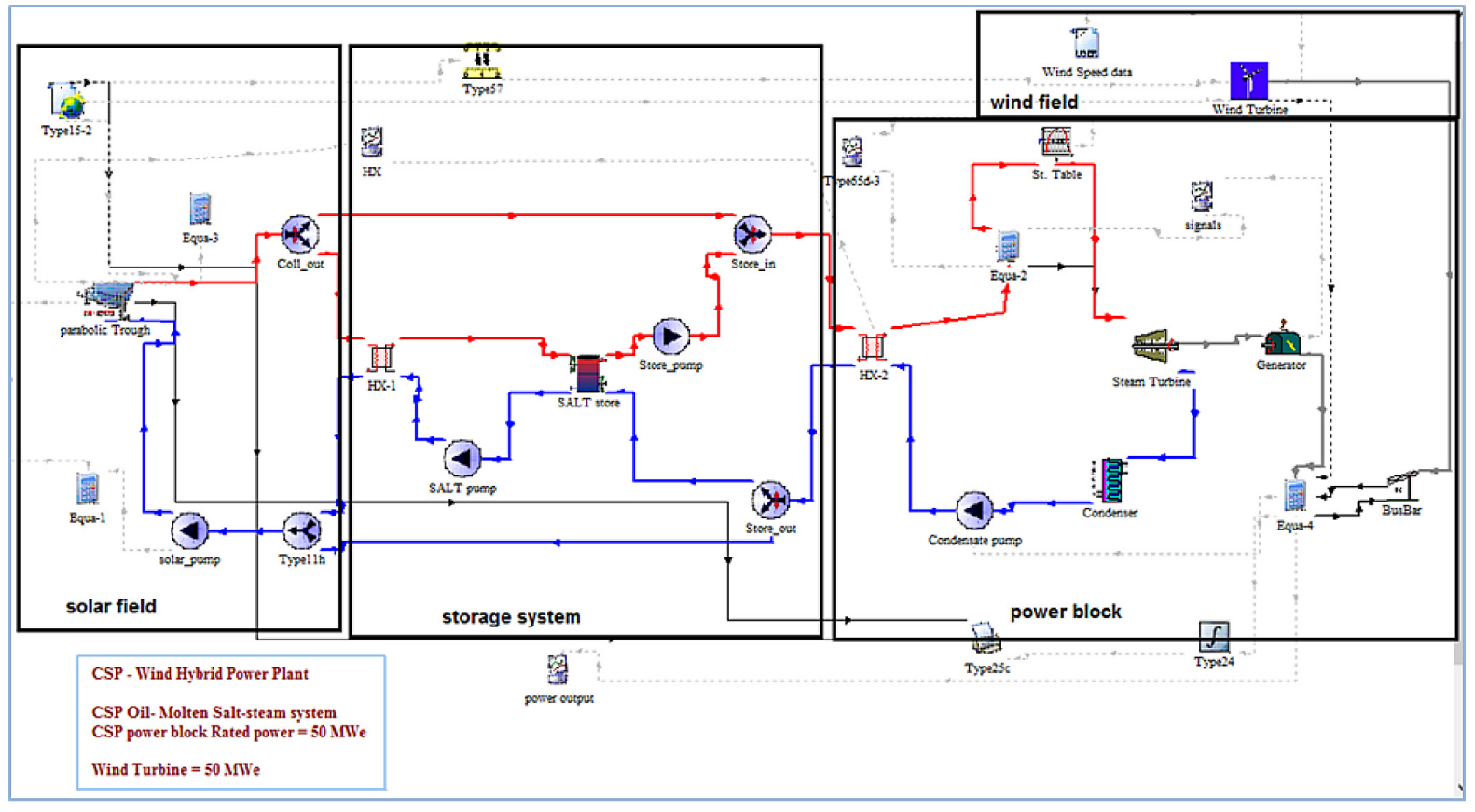

Figure 2. TRNSYS model of the hybrid system plant

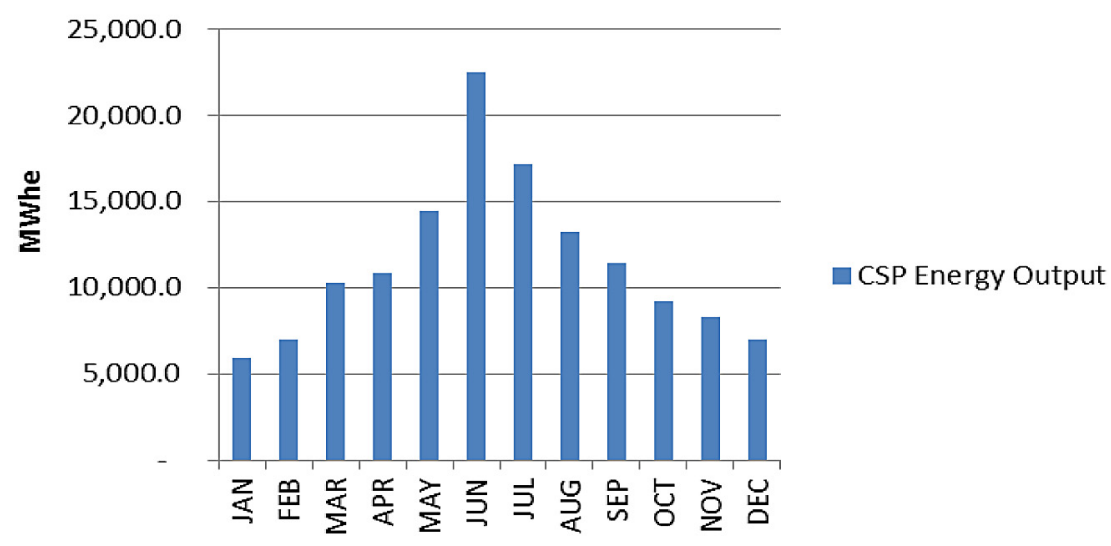

Figure 3. Monthly CSP energy production

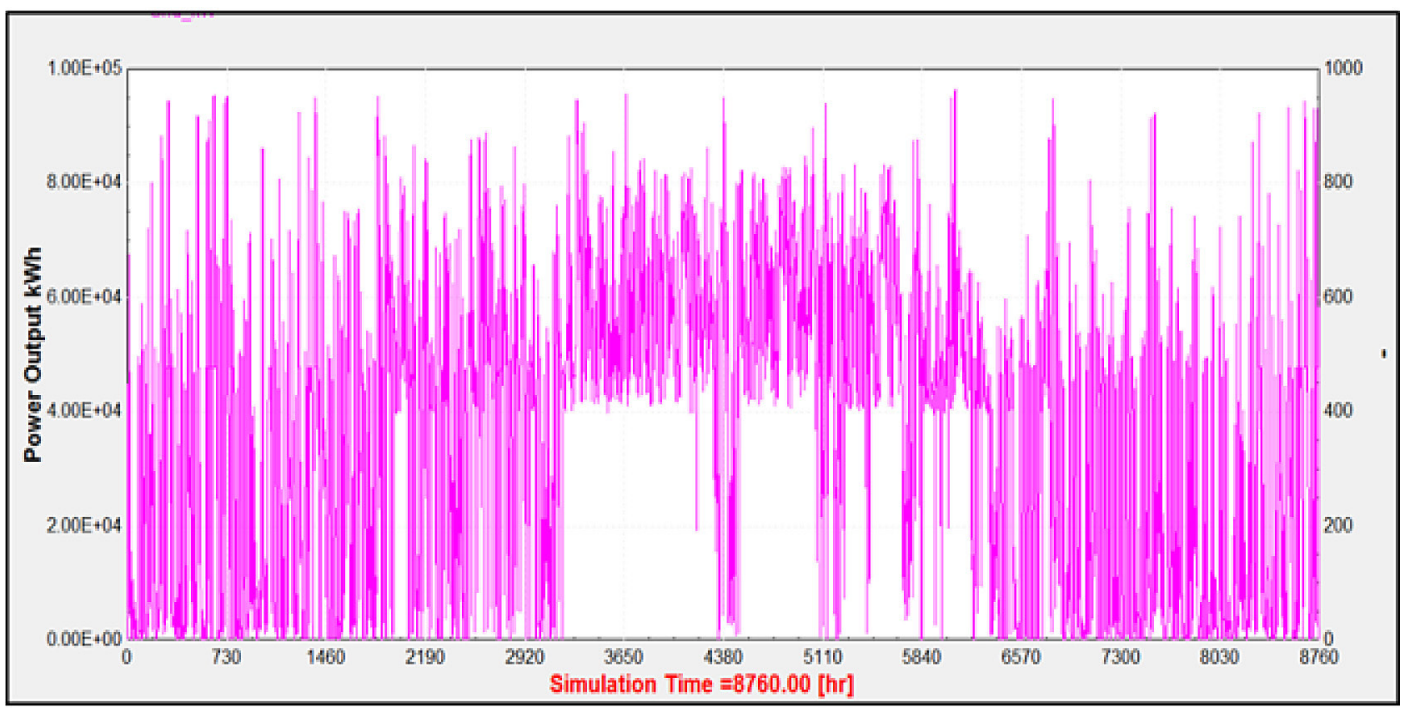

Figure 4. Power output of the hybrid CSP-Wind system plant 


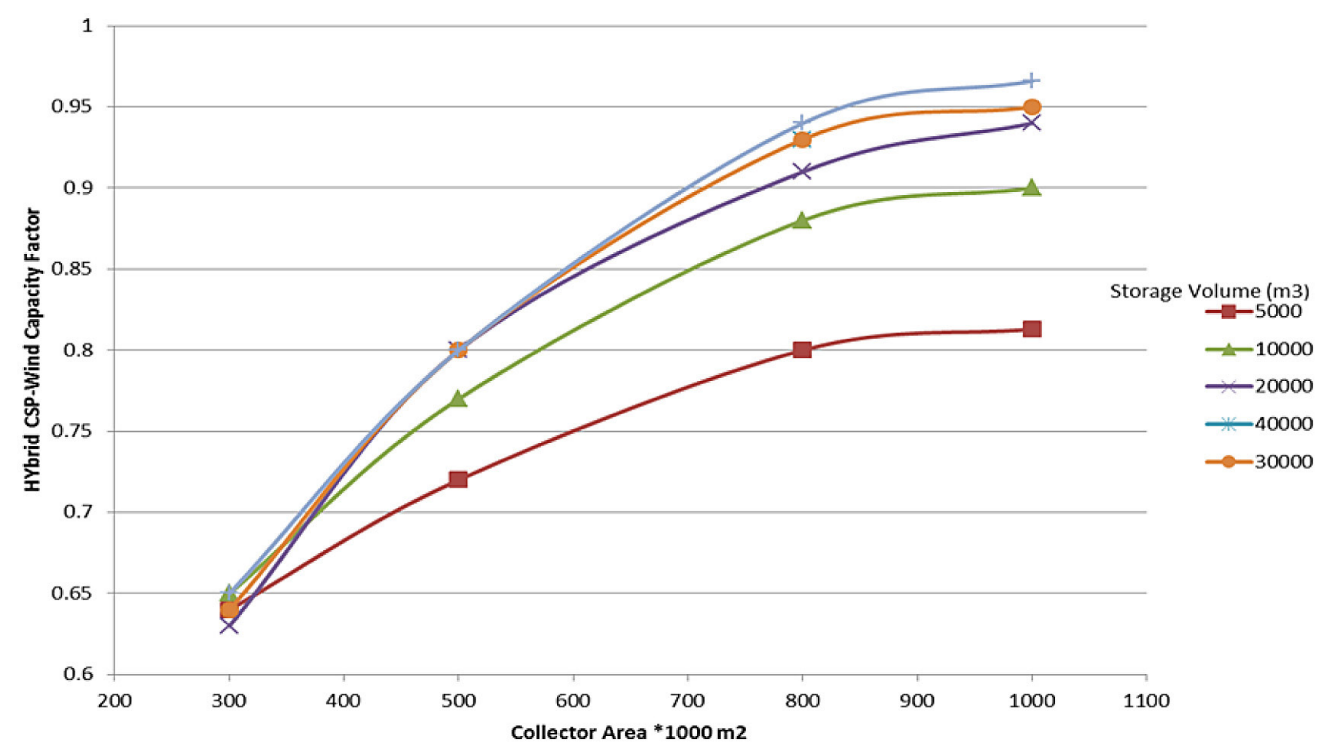

Figure 5. Capacity factor for the hybrid CSP-Wind plant with changing collector area and storage volume

days, and to increase the capacity factor of the proposed PTC system, the solar multiple should be enlarged. In order to calculate the optimal solar field area; different trials were carried out, i.e. by changing the solar multiple (SM) value between $1-3.5$. The same procedure was applied for the options. The results are summarized in Figure 5.

In the figure above, it may be noticed that the overall capacity factor of the system plant increases when the solar collector area is increased as well. Furthermore, it should be noticed that when the volume of the storage tank increases, the capacity factor of the system plant increases too.

Increasing the volume of the storage tank will enhance the capacity factor of the system plant until the enhancement reaches a limit, where the capacity factor increases by small percentage. The capacity factor for the system plant at a solar collector area $800,000 \mathrm{~m}^{2}$ which corresponds to solar multiple $(\mathrm{SM})=2.6$, and when the storage volume is $30,000 \mathrm{~m}^{3}$ is 0.77 . This capacity factor happens also where the collector area 1000,000 $\mathrm{m}^{2}$ which corresponds to $\mathrm{SM}=3.3$, and when the storage volume is $20,000 \mathrm{~m}^{3}$. Further increase of the solar collector area and storage volume results in a little enhancement of the capacity factor. The first option where the $\mathrm{SM}=2.6$, and the storage volume $=30,000 \mathrm{~m}^{3}$ is chosen as the optimum combination of the collector area and the storage volume. From the economical point of view, the increase in the storage volume is less expensive than the increase of the total collector area.

The power generation from the CSP plant reached $49.5 \mathrm{MW}$, and the storage capacity reached
5.2 hours. The monthly energy production from the CSP and wind power plants are presented in Figure 6 . The power output of the wind plant during the entire year is illustrated in Figure 7.

The figure above indicates that the rated power of the wind turbine reached $48,000 \mathrm{~kW}$; hence, the capacity factor of the wind farm could be calculated from the following equation: $\mathrm{CF}$ (wind) $=\sum$ wind turbine output per year/ (rated power*8760) $=112,770,823.6 / 420,480,000=$ 0.27 . On the other hand; the power output of the CSP $\left[S M=2.6\right.$, storage size $=\left[30,000 \mathrm{~m}^{3}\right]$ plant for the selected location is presented in Figure 8.

This figure shows that the rated power output of the CSP plant was $49,503 \mathrm{~kW}$, and hence, the capacity factor for the CSP plant is:

$\mathrm{CF}(\mathrm{CSP})=\sum \mathrm{CSP}$ energy output/rated power .

$8760=309,643,876 / 438,000,000=0.71$

The overall efficiency of the plant calculated as the following:

$$
\begin{gathered}
\sum \mathrm{CSP} \text { output energy } / \sum \mathrm{DNI}= \\
309,643,876 / 9,754,599.6=0.31
\end{gathered}
$$

\section{STORAGE CAPACITY}

In order to calculate the storage capacity of the model storage system, the outlet temperature of the solar collector under study is shown in Figure 9.

Figure 9 indicates that the outlet temperature of the solar collector dropped below $220^{\circ} \mathrm{C}$ in several hours during the year, but the CSP plant 


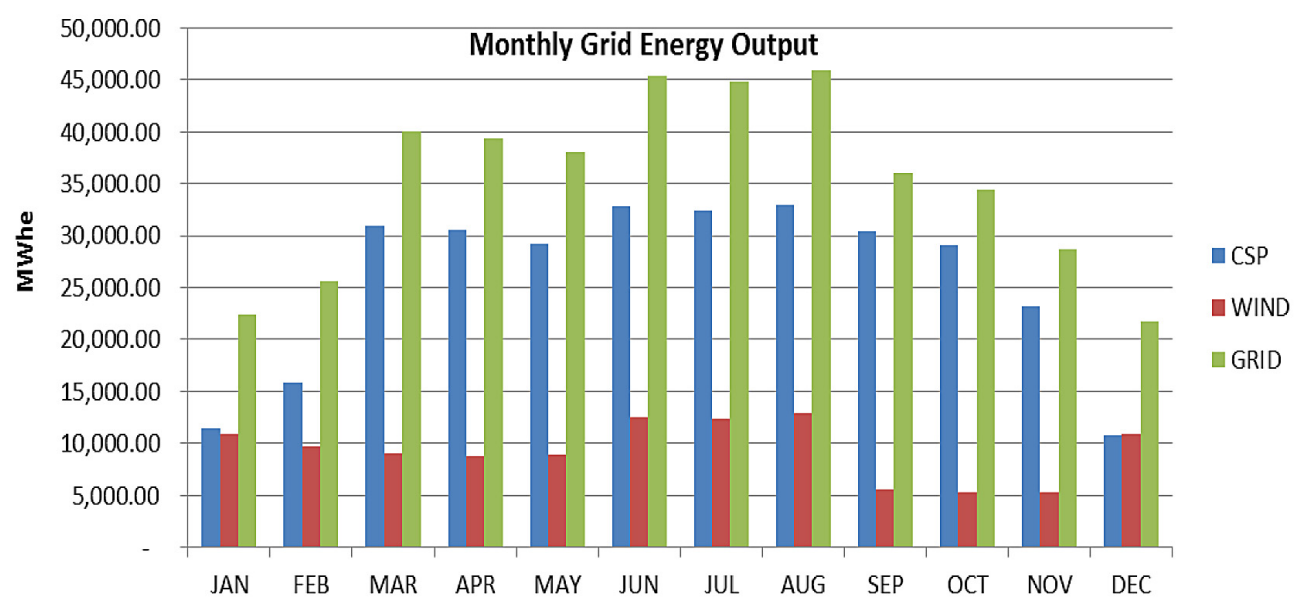

Figure 6. Monthly grid energy output

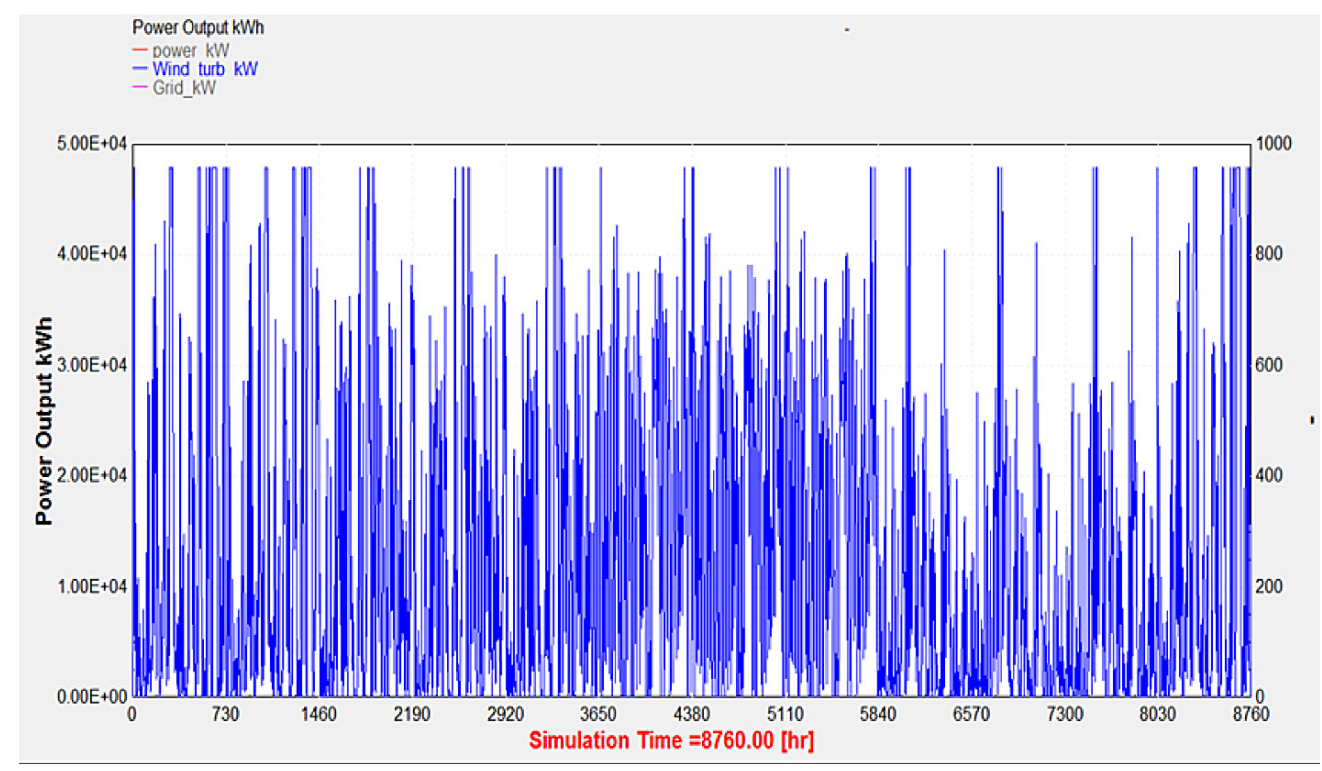

Figure 7. Wind power output

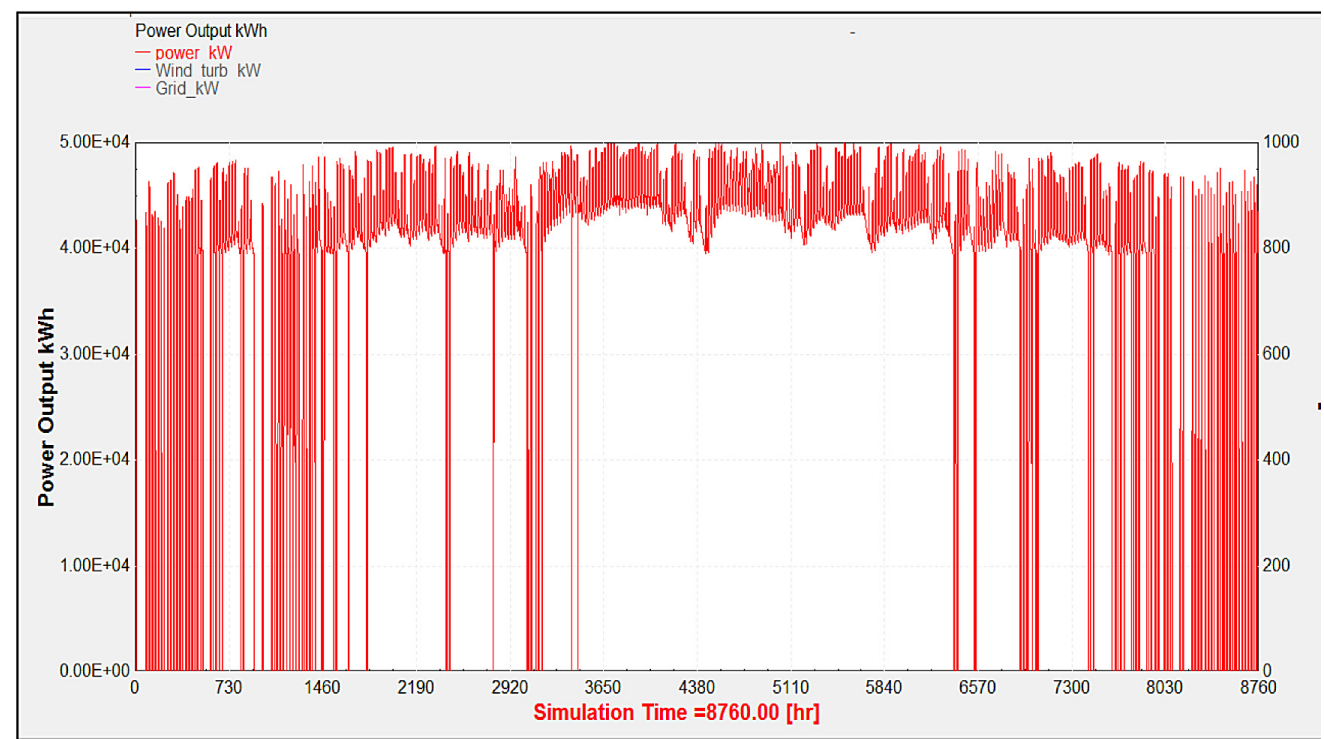

Figure 8. CSP power output 


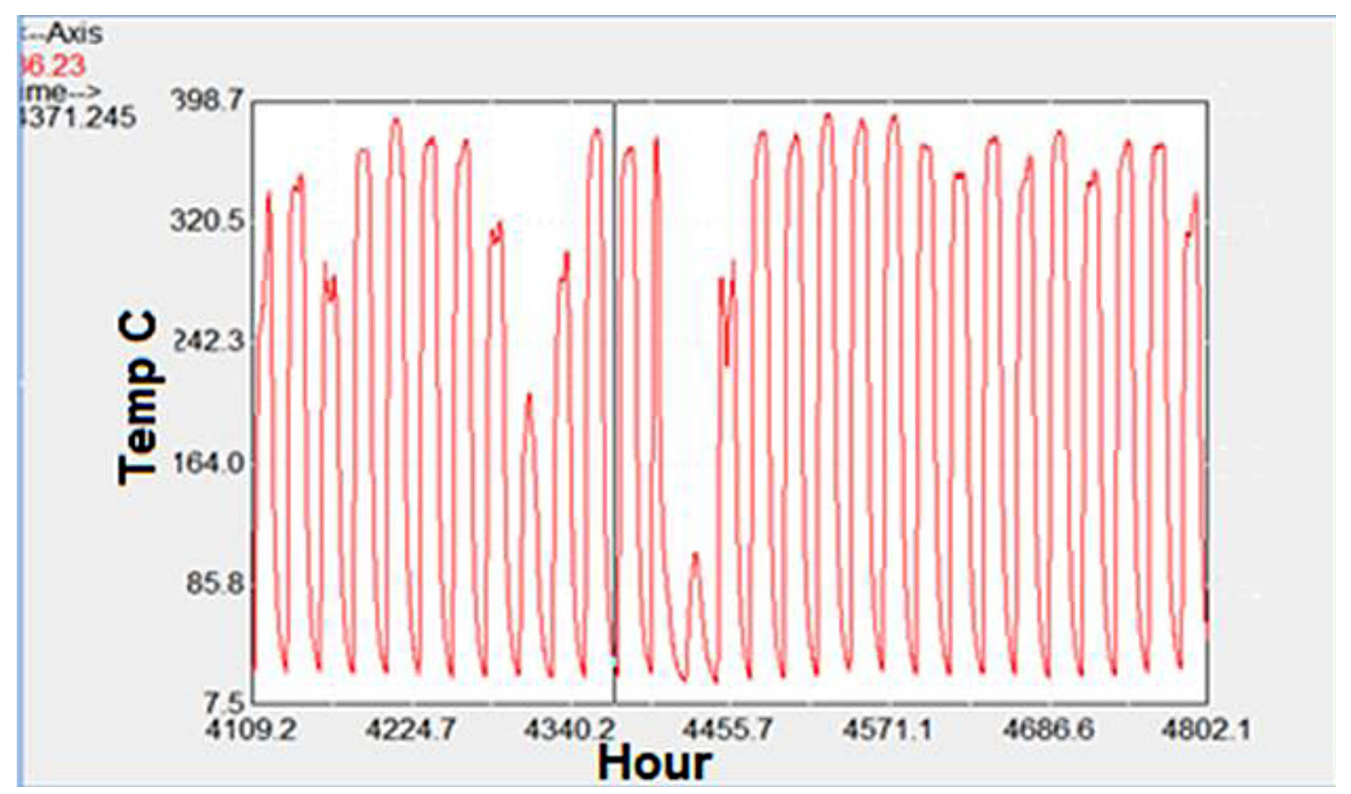

Figure 9. Collector output temperature

was still delivering energy output, like in the case of the drop around the $15^{\text {th }}$ June, when the outlet temperature of the solar collector reached $50^{\circ} \mathrm{C}$ Consequently, following the similar situations in the output power, and outlet temperature of the collector files, around 40 weekly storage capacity of our model (about 5-6 hours daily) was counted.

\section{ECONOMIC ASSESSMENT OF THE HYBRID CSP WIND PLANT}

This section explains the LCOE approach developed and used for the calculation of the cost of solar CSP and Wind electricity. LCOE enables the energy planners and policy makers to compare the generation costs of conventional and renewable resources. Equation 1 describes the LCOE model used in Jordan.

$$
L C O E=\frac{i+\sum_{t=0}^{T}\left(\boldsymbol{O}_{t}\right) /(1+r)^{t}}{\sum_{t=\mathbf{0}}^{T} S_{t=\mathbf{0}_{t}}(1-d)^{t}}
$$

where: $L C O E$ - levelized cost of electricity per unit in period $\mathrm{t}$,

$T$ - economic life of project,

$t-$ year,

$I_{t}$ - initial investment,

$\mathrm{O}_{t}$ - operation and maintenance costs,

$r$-discount rate,

$S_{t}$ - rated energy output in period $\mathrm{t}=0$,

$d$ - annual module degradation factor.
When submitting all the assumption parameters - for the wind plant - in LCOE equation (equation 1):

$$
\begin{gathered}
L C O E=\frac{58600000+\sum_{t=0}^{25}(+2 \% * 58600000) /(1+6 \%)^{t}}{\sum_{t=0}^{25} 112,770,823.6 *(1-1 \%)^{t}} \\
L C O E=0.029 \mathrm{JOD} / \mathrm{KWh}
\end{gathered}
$$

Following the same analysis for the CSP energy production and substitute in equation 1 :

$$
\begin{aligned}
& L C O E=\frac{29000000+\sum_{t=0}^{25}(3 \% * 290000000) /(1+6 \%)^{t}}{\sum_{t=0}^{25} 309643876 * 1,000(1-0.2 \%)^{t}} \\
& L C O E=0.058 \mathrm{JOD} / \mathrm{KWh}
\end{aligned}
$$

By adopting the same procedure and calculating the overall LCOE for the Hybrid CSP/wind System, it was found to equal $0.0454 \mathrm{JOD} / \mathrm{kWh}$.

\section{CONCLUSIONS}

The Hybrid system plant is simulated and a performance analysis is conducted in the paper, yielding substantial results. It is found that operating the wind plant alone will result in a capacity factor of $27 \%$. In addition, operating the CSP plant with 5 hours energy storage system results in a capacity factor of $71 \%$. The hybridization of the CSP and wind power plant results in the overall capacity factor of $94 \%$.

From an economical point of view, the LCOE after operating the wind plant reaches about 0.029 $\mathrm{JOD} / \mathrm{kWh}$, while the LCOE for the CSP plant reaches about $0.058 \mathrm{JOD} / \mathrm{kWh}$. Hybridization of the wind and CSP energy sources leads to overall 
LCOE about $0.045 \mathrm{JOD} / \mathrm{kWh}$. The accumulative revenues of the CSP plant with 5 hours energy storage after 25 years of operation are about 4.5 times the accumulative revenues of the wind plant on the same scale.

\section{Acknowledgment}

We would like to convey our gratitude to all of the faculty and staff in the Department of Mechanical Engineering at the University of Jordan. We wish to extend our thanks to Eng. Nidal Abdullah, from National Energy Research Center, for his support and patience.

\section{REFERENCES}

1. Chaanaoui M., Vaudreuil S., Bounahmidi T. 2016. Benchmark of Concentrating Solar Power Plants: Historical, Current and Future Technical and Economic Development. Procedia Computer Science, 83(Seit), 782-789. https://doi.org/10.1016/j. procs.2016.04.167.

2. Chen H.H., Kang H.Y., Lee A.H.I. 2010. Strategic selection of suitable projects for hybrid solar-wind power generation systems. Renewable and Sustainable Energy Reviews, 14(1), 413-421. https://doi. org/10.1016/j.rser.2009.08.004

3. Chen R., Sun H., Guo Q., Li Z., Deng T., Wu W., Zhang B. 2015. Reducing Generation Uncertainty by Integrating CSP with Wind Power: An Adaptive Robust Optimization-Based Analysis. IEEE Transactions on Sustainable Energy, 6(2), 583-594. https://doi.org/10.1109/TSTE.2015.2396971

4. Dale M. 2013. A Comparative Analysis of Energy Costs of Photovoltaic, Solar Thermal, and Wind Electricity Generation Technologies. Applied Sciences, 3(2), 325-337. https://doi.org/10.3390/app3020325

5. González A., Riba J.R., Rius A., Puig R. 2015. Optimal sizing of a hybrid grid-connected photovoltaic and wind power system. Applied Energy, 154, 752 762. https://doi.org/10.1016/j.apenergy.2015.04.105

6. Kost C., Pfluger B., Eichhammer W., Ragwitz M. 2011. Fruitful symbiosis: Why an export bundled with wind energy is the most feasible option for North African concentrated solar power. Energy Policy, 39(11), 7136-7145. https://doi.org/10.1016/j. enpol.2011.08.032

7. Li T., Liu Y., Wang D., Shang K., Liu J. 2015. Optimization analysis on storage tank volume in solar heating system. Procedia Engineering, 121, 1356-
1364. https://doi.org/10.1016/j.proeng.2015.09.019

8. Liqreina A., Qoaider L. 2014. Dry cooling of concentrating solar power ( CSP ) plants, an economic competitive option for the desert regions of the MENA region. Solar Energy, 103, 417-424. https:// doi.org/10.1016/j.solener.2014.02.039

9. MEMR. (2015). Annual Report. Retrieved from http://www.memr.gov.jo/Pages/viewpage. aspx?pageID $=190$

10. meteonorm. (2016). http://www.meteonorm.com.

11. NEPCO. 2015. Annual Report 2015.

12. Pousinho H.M.I., Esteves J., Mendes V.M.F., Collares-Pereira M., Pereira Cabrita C. 2016. Bilevel approach to wind-CSP day-ahead scheduling with spinning reserve under controllable degree of trust. Renewable Energy, 85, 917-927. https://doi. org/10.1016/j.renene.2015.07.022

13. Qoaider L., Liqreina A. 2015. Optimization of dry cooled parabolic trough ( CSP ) plants for the desert regions of the Middle East and North Africa (MENA). Solar Energy, 122, 976-985. https://doi. org/10.1016/j.solener.2015.10.021

14. Serrano-lópez R., Fradera J., Cuesta-López S. 2013. Molten salts database for energy applications.

15. Servert J., López D., Cerrajero E., Rocha A.R., Pereira D., González L. 2016. Tailoring HYSOL: Solar Energy Contribution to Reach Full Dispatchability and Firmness in Target Markets. Procedia Computer Science, 83, 1134-1141. https://doi. org/10.1016/j.procs.2016.04.234

16. Sh. Al-raqqad. 2016. Computer Modeling of a Hybrid Solar Power Tower with Thermal Storage and Integrated Photovoltaic as a Base-Load Power Source for Aqaba Special Economic Zone, Master thesis, University of Jordan

17. Sioshansi R., Denholm P. 2013. Benefits of Colocating Concentrating Solar Power and Wind. Sustainable Energy, IEEE Transactions on, 4(4), 877-885. https://doi.org/10.1109/TSTE.2013.2253619

18. Solar Millennium AG 2008. The parabolic trough power plants Andasol 1 to 3. The largest solar power plants in the world - technology premiere in Europe. Report oeko1_159_presse_engl_0309_02.

19. Vick B.D., Moss T.A. 2013. Adding concentrated solar power plants to wind farms to achieve a good utility electrical load match. Solar Energy, 92, 298-312. https://doi.org/10.1016/j.solener.2013.03.007.

20. Yunna W., Geng S. 2014. Multi-criteria decision making on selection of solar-wind hybrid power station location: A case of China. Energy Conversion and Management, 81, 527-533. https://doi. org/10.1016/j.enconman.2014.02.056 